\title{
NACIONALISMO, RELIGIÃO E (DES)IGUALDADE DE SEXO EM ISRAEL PELO PRISMA DO DIREITO DA FAMILIA*
}

\author{
Ruth Halperin-Kaddari \\ Yaacov Yadgar ${ }^{* *}$
}

\section{RESUMO}

Este artigo mostra que o conflito violento e duradouro mantido por Israel com os seus vizinhos árabes está pesando de modo decisivo sobre as relações de gênero. Aos olhos de muitos judeus israelenses, trata-se de uma luta pela sobrevivência do Estado judeu, que eclipsou a maioria das outras questões de ordem civil e social - tais como a igualdade dos sexos e os direitos das mulheres - julgadas 'secundárias', por comparação. Daí a perpetuação de práticas discriminatórias, até a sujeição aberta das mulheres em Israel. $O$ artigo trata mais especificamente da questão do matrimônio e do divórcio, tomada como reveladora. Ela joga luz sobre o papel que os movimentos feministas - religioso judeu, de um lado, e árabe-palestino, do outro lado - exerceram na reforma do direito da família.

Palavras-chave: Israel. Nacionalismo. Religião. Judaísmo. Discriminações. Direitos das Mulheres. Matrimônio. Divórcio. Movimentos Feministas.

\section{NATIONALISME, RELIGION ET (IN)ÉGALITÉ DE SEXE EN ISRAËL AU PRISME DU DROIT DE LA FAMILLE}

\section{RÉSUMÉ}

Cet article montre que le conflit violent et durable entretenu par Israël avec ses voisins arabes pèse de façon décisive sur les rapports de genre. Aux yeux de nombreux juifs israéliens, il s'agit là d'une lutte pour la survie de l'État juif, qui a éclipsé la plupart des autres

* Traduzido da versão francesa para o português por Etienne Higuet. O texto original em francês, "Nationalisme, religion et (in)égalité de sexe en Israël au prisme du droit de la famille", Cahiers du Genre, 2012/3 (HS n 3 ), p. 119-137, foi traduzido do inglês por Jacqueline Heinen.

** A autora e o autor querem exprimir a sua gratidão à sua assistente de pesquisa, Marina Rozier, pela ajuda preciosa que ela lhes prestou. 
questions d'ordre civil et social - telles que l'égalité des sexes et les droits des femmes - jugées 'secondaires' par comparaison. D'où la perpétuation de pratiques discriminatoires, voire la sujétion ouverte des femmes en Israël. L'article porte plus spécifiquement sur la question du mariage et du divorce, prise comme un révélateur. Elle met en lumière le rôle que les mouvements féministes — religieux juif, d'une part, et arabo-palestinien, d'autre part — ont joué dans la réforme du droit de la famille.

Mots-clés: Israël. Nationalisme. Religion. Judaïsme. Discriminations. Droits des Femmes. Mariage. Divorce. Mouvements Féministes.

Quando se pergunta a respeito do vínculo entre política e religião e suas consequências quanto às relações de gênero, o caso de Israel aparece como único em muitos aspectos. Este país foi criado como Estado do povo judeu (ver a Declaração de Independência) e se definiu (nas suas Leis Fundamentais) como Estado judeu e democrático. A estrutura jurídica de Israel nunca incluiu uma separação formal entre Estado e religião, a qual está estreitamente associada a todos os níveis de governança - sociedade política e sociedade civil. A luta contra o domínio do dogma religioso sobre o matrimônio e o divórcio faz parte do programa das organizações de mulheres desde o mandato britânico sobre a Palestina, mas com muito pouco sucesso. A competência exclusiva das leis religiosas continua atual na matéria em questão, e o casamento civil não existe em Israel. Embora a sociedade civil seja muito heterogênea, a maior parte dos/as seus/as membros admite a dimensão étnico-religiosa em diversos níveis, seja a respeito das questões de identidade (formal, individual ou de grupo) ou das questões de governança (interna ou externa).

Um dos outros traços específicos da situação israelense pesa também fortemente sobre as relações de gênero: a continuação do conflito violento entre Israel e os seus vizinhos árabes. Este conflito eclipsou quase todas as outras questões de ordem civil e social, cuja importância aparece menor em relação com a preocupação primeira preservar a existência e a segurança do Estado. Isso vale principalmente para problemas tão urgentes como a igualdade dos sexos e os direitos das mulheres, com o que decorre deles: a manutenção de práticas dis- 
criminatórias, até de comportamentos abertamente repressivos para com elas. Uma prova disso está no modo de tratar a luta a favor do casamento civil e do divórcio como um não problema.

\section{NAÇÃO E RELIGIÃO: ALGUMAS CONSIDERAÇÕES ELEMENTARES}

O Estado de Israel se define como Estado-nação laico e democrático, embora não haja nenhuma separação entre religião e política, mas, ao contrário, um entrelaçamento (pelo menos, no plano teórico) entre nacionalismo étnico de tipo laico e tradicionalismo religioso de tipo ortodoxo. Encontramos a mesma complexidade nas duas leis fundamentais, comumente consideradas como uma quase-Constituição, que qualificam Israel como Estado ao mesmo tempo 'democrático' e 'judeu'.

No plano jurídico-formal, em primeiro lugar, o Estado de Israel confere à religião judaica a honra suprema de definir sua identidade coletiva, por meio de uma série de leis a respeito da cidadania, da imigração, e do código do estatuto pessoal (Fogiel-Bijaoui, 2003). A mais importante é a lei do retorno de 1950. Ela proclama: "Todo judeu tem o direito de vir nesse país como oleh [imigrante]" $(\S 1)$, e o critério do 'direito de retorno' não é outro que a definição religiosa ortodoxa de 'quem é judeu' - isto é, ter nascido de mãe judia (§ 4B). Ora, toda pessoa que possui o direito ao retorno adquire automaticamente a cidadania israelense em virtude da lei de 1952 sobre a cidadania. Não menos importante é a lei dos tribunais rabínicos de 1953, decretando (no § 2) que o casamento e o divórcio dos/as judeus/judias devem necessariamente ser conformes à lei judaica, o que exclui toda hipótese de casamento misto no solo israelense, já que o casamento das mulheres e dos homens judeus com não judeus/judias é proibido. A lei do retorno e a lei dos tribunais rabínicos são muitas vezes percebidas como elementos-chave da identidade judaica do Estado de Israel (Shachar, 2000).

A lei do retorno é, de fato, uma das vertentes do código do estatuto pessoal herdado do domínio otomano sobre a Palestina e transmitido ao Estado de Israel através do mandato britânico: as questões relativas ao estatuto pessoal estão definidas nele em função da pertença religiosa (em outras palavras, das leis religiosas) das partes envolvidas. Alguns sugeriram que a manutenção de tal regime, que garante o vínculo formal 
de todos os grupos de origem étnica e nacional diferente vivendo em Israel com suas respectivas religiões, atende a uma necessidade mais profunda, embora mascarada, de preservar a identidade distinta de cada um dos grupos que compõem a sociedade israelense e de delimitar assim mesmo as fronteiras que os separam (Fogiel-Bijaoui, 2003). A esse título, haveria um interesse compartilhado dos/as judeus/judias e dos/as Árabes em perpetuar tal disposição. Mas, ao mesmo tempo, isso tende a perenizar a desigualdade entre eles/as, na medida em que a instituição jurídica formal da segregação étnica inibe, de algum modo, a luta dos/as cidadãos/cidadãs árabes por uma igualdade plena. Com efeito, a associação entre cidadania israelense e 'judaicidade' (caráter étnico judeu) impõe aos não judeus/judias de Israel (quase todos/as muçulmanos/as árabes) um estatuto duvidoso de cidadãos/cidadãs desclassificados/as. Favorecendo explicitamente a imigração judia, a lei do retorno formaliza a desigualdade jurídica perante o Estado israelense. Isso se manifesta nas discussões sem fim a respeito da 'ameaça demográfica' e nas medidas políticas que visam a preservar uma maioria judaica em Israel (Bem-Shemesh, 2006, p. 47; Stopler, 2008). Nesse ponto, como em outros - ajuda orçamentária, infraestrutura, aquisição de terras, seguridade social, educação e, mais recentemente, mudança de política a respeito do reagrupamento familiar envolvendo palestinos/ as da Cisjordânia - os/as israelenses não judeus/judias se veem impor na prática, senão em princípio, uma cidadania de segunda categoria (Davidov et al., 2005; Zilbershats, 2006).

Usa-se o termo de 'democracia étnica' para designar Israel. Trata-se de um sistema cumulando dois princípios contraditórios: o 'princípio democrático', que assegura a igualdade em direito e a igualdade de tratamento de todos/as os/as cidadãos/cidadãs, e o 'princípio étnico', que visa a moldar um Estado-nação homogêneo, ao privilegiar a maioria étnica (Smooha, 1997). Essa dualidade mantém a permanência do conflito israelo-árabe. A esse respeito, a extrema militarização da sociedade e da cultura israelenses contribui para reforçar a prioridade concedida aos 'problemas de segurança' sobre praticamente todos os outros, com as graves consequências orçamentárias que decorrem disso (Bem-Eliezer, 1995). Convém ressaltar que, ao longo de toda a história do Estado Is- 
raelense e do movimento sionista (inclusive na era pré-estatal), o vínculo nodal entre o Estado laico e a tradição judaica (religiosa) foi raramente questionado. Com exceção de alguns grupos de oposição marginais, a grande maioria dos/as judeus/judias israelenses reivindica o apego de Israel à cultura, aos símbolos, ao povo judeu, e até à religião judaica em si - o que não impede a maioria deles/as de se definir como laicos/as, ou pelo menos como 'não-religiosos/as' (Levy et al., 1993).

Israel é uma democracia parlamentar fundada numa representação proporcional ligada a eleições periódicas, livres e abertas. Há, em consequência, numerosos partidos políticos, dos quais muitos visam a representar segmentos definidos da sociedade israelense, inclusive correntes religiosas - que encarnam diversas variantes no que diz respeito ao grau de religiosidade, à origem étnica ou à atitude em relação com o sionismo. Este sistema de coligação incita a fazer do consenso nacional (judeu, mais precisamente) a principal ferramenta de governança, e permite aos grupos minoritários (sobretudo os partidos judeus religiosos) exercer uma influência única sobre o processo de decisão. Uma das principais consequências desta busca de consenso (judeu) foi a incapacidade da Assembleia Constituinte israelense de adotar uma constituição escrita, como se verá mais adiante.

O caráter etnocentrado do discurso judaico é decisivo aqui, já que o mecanismo de representação política fundado no consenso exclui sistematicamente os partidos que representam a minoria árabe. Assim, as coligações governamentais - inclusive as formadas pela esquerda em princípio mais pacifista (pelo menos no papel) - preferiram firmar acordos frágeis entre partidos judeus, em vez de associar os partidos árabes ao poder. Na mesma linha, o discurso político comum em Israel parece tratar como axioma a ideia de que nenhum governo deveria apoiar-se na base árabe, quando se trata de fazer concessões às nações árabes. Por conseguinte, outros pequenos partidos, principalmente aqueles que podem ser qualificados de 'religiosos' (judeus), adquiriram um peso decisivo, já que os dois principais blocos dependem do seu sustento para formar a coligação vigente. 


\section{AS MULHERES EM ISRAEL: O QUADRO JURÍDICO}

Progressos sensíveis foram realizados em Israel quanto à qualidade de vida das mulheres (esperança de vida, mortalidade materna e infantil, nível de alfabetização, idade matrimonial, etc.). Contudo, eles dizem respeito sobretudo às judias e muito menos às árabo-palestinenses. Por outro lado, não se registra nenhum progresso nos domínios tais como a participação na vida pública, o meio de trabalho, a equidade salarial ou as oportunidades em matéria de formação'. Além disso, a maior parte dos avanços tocando ao estatuto das mulheres durante os quarenta primeiros anos de existência do Estado decorria dos progressos mais gerais do país no plano socioeconômico (Halperin-Kaddari, 2004). Há, enfim, distâncias evidentes entre as leis colocadas no papel e a realidade social, assim como entre o direito da família e outras esferas jurídicas. Em matéria de direitos das mulheres, o sistema israelense foi muitas vezes descrito como portador de medidas progressistas no plano legislativo e judiciário, sobretudo a partir dos anos 1980, mas como sofrendo de uma falta global de controle no que toca à sua aplicação.

Por uma série de razões sociais e políticos, Israel não adotou uma constituição escrita quando da sua criação. Diversas tentativas foram feitas no decorrer dos anos para entrar em acordo a respeito de uma carta dos direitos humanos, mas um dos principais obstáculos encontrados foi a questão da igualdade dos sexos e da igualdade do estatuto das mulheres perante a lei. Por causa do domínio das leis religiosas sobre o direito da família, uma igualdade plena das mulheres é ilusória. O esquema de subordinação da igualdade dos sexos aos valores religiosos foi formulado muito claramente desde 1951, com a adoção da lei sobre a igualdade dos direitos das mulheres, da qual uma cláusula estipula que ela não se aplica ao matrimônio e ao divórcio. Transparece igualmente na Lei Fundamental atual (solução escolhida por Israel no lugar de uma constituição completa), da qual uma cláusula isenta as leis existentes de uma revisão jurídica. Embora o código do estatuto pessoal proceda do sistema dos Millet do Império Otomano², a sua manutenção no decorrer dos sessenta anos de existência do país equivale a uma profissão de fé

Para uma análise mais detalhada, ver Halperin-Kaddari, 2009.

O termo otomano 'Millet' designa uma comunidade religiosa legalmente protegida. 
que acaba favorecendo explicitamente a cultura patriarcal à custa dos direitos individuais e dos valores liberais no seu conjunto, assim como viola os direitos das mulheres e o princípio de igualdade dos sexos (Halperin-Kaddari, 2000).

Até 2001, os tribunais muçulmanos tinham uma competência exclusiva sobre todas as questões relativas ao estatuto pessoal, como as questões de filiação, de autoridade conjugal e de guarda das crianças. Assim, sua competência era mais extensa que a dos outros tribunais religiosos, e a possibilidade para as muçulmanas de se dirigirem às instâncias cíveis era ainda mais restrita que para as mulheres de outros grupos. As coisas mudaram no fim de 2001, quando uma coligação emanando de organizações de mulheres muçulmanas conseguiu, no termo de seis anos de luta, fazer modificar o direito da família. Doravante, a respeito das questões de estatuto pessoal, as requerentes podem recorrer a duas jurisdições paralelas (civil ou religiosa), conforme a sua escolha.

Precisemos que, nos tribunais muçulmanos, o estatuto das mulheres está fortemente comprometido pela lei islâmica vigente - a charia (ou chari'a) - muito discriminatória com elas. Ela autoriza, em particular, a poligamia e, se ela reconhece o talâq ou divórcio unilateral' ${ }^{3}$ é apenas para os homens. Sua aplicação depende fortemente da estrutura patriarcal e das normas culturais da sociedade árabe em Israel (Abdo, 1997; Abou-Ramadan, Monterescu, 2008).

A respeito do casamento e do divórcio, a divisão das competências entre jurisdições cíveis e religiosas tem uma incidência muito mais forte para os/as judeus/judias que para os/as muçulmanos/as, levando em conta a autoridade exclusiva dos tribunais rabínicos na matéria em questão. Todo judeu/judia de Israel, seja ele/a religioso/a ou laico/a, só pode casar ou divorciar perante eles. Ora, eles são constituídos exclusivamente de homens e inteiramente submissos a uma leitura ortodoxa da lei religiosa. Entretanto, todas as outras questões ligadas ao divórcio - da guarda das crianças à repartição dos bens - estão sob a jurisdição concorrente dos tribunais civis (da família) e dos tribunais religiosos. Registrar uma queixa perante um deles proíbe que o caso seja tratado

3 O termo talâq designa, do ponto de vista do Islã, a interrupção provisória de uma relação que precisa ser reconsiderada. Logo, não se trata de uma ruptura definitiva da relação. 
pelo outro. Em consequência, num divórcio, cada parte procura vencer ao dirigir-se à instância que percebe como mais favorável nos pontos que dependem da sua autoridade. Já que os tribunais rabínicos se guiam pela lei judaica, aplicam as regras de procedimento religioso e ignoram quase sempre o direito civil, as sentenças que eles formulam são percebidas como favoráveis ao marido, enquanto o recurso aos tribunais civis parece mais adequado para a mulher (Rosen-Zvi, 1990; Shifman, 1995).

A construção de gênero na lei judaica do matrimônio e do divórcio, assim como interpretada e aplicada pelos tribunais rabínicos, implica numa inferioridade e vulnerabilidade inegáveis das mulheres. Numa palavra, esta lei concebe o casamento como uma transação de sentido único, pela qual o homem assume a mulher como noiva, e não o contrário. Ela consagra a desigualdade e a discriminação em matéria de direitos e de obrigações mútuas dos/as cônjuges durante o casamento, e sanciona severamente o divórcio, à custa das mulheres (Halperin-Kaddari, 2000).

Uma das desigualdades fundamentais entre homens e mulheres diz respeito à obtenção da ata de divórcio, isto é, o get. Segunda a lei judaica, a outorga voluntária do get pelo marido é uma condição absoluta para validar o divórcio. Embora o consenso da mulher seja também necessário para esse fim, os homens são autorizados a casar de novo sem ter conseguido o get numa série de casos, ao passo que as mulheres nunca têm esse direito (Haut, 1983). Além disso, se uma mulher que se viu recusar o get tivesse filhos/as de outro homem, esses/as seriam qualificados/as de mamzerim, ou bastardos/as - um estatuto que the proíbe casar no seio da comunidade judaica, salvo com convertidos/as ou outros/as mamzerim. Ao contrário, nenhum estigma atinge os/as filhos/ as de um homem que ainda não se divorciou. Enfim, os motivos que determinam as decisões rabínicas sobre a necessidade do divórcio são muito diferentes para os homens e para as mulheres. Por exemplo, um único caso de adultério da parte da mulher constitui um motivo imediato, obrigatório e irrevogável de divórcio, ao passo que apenas relações extraconjugais prolongadas do lado do marido são uma base de divórcio - e apenas aos olhos de certos tribunais (Falk, 1973; Halperin-Kaddari, 2000). Até muito recentemente, até a preservação dos bens da mulher 
dependia das modalidades do divórcio. De fato, a lei sobre os direitos de propriedade dos/as cônjuges de 1973 condiciona a repartição dos bens matrimoniais à outorga do get, e o marido podia negar os direitos da sua esposa ao lhe recusar o get. Foram necessários dez anos de luta obstinada das organizações de mulheres judias (sobretudo religiosas) para modificar a lei (Halperin-Kaddari, 2008).

Em regra geral, o marido possui, assim, um direito quase absoluto sobre o get, do qual a mulher precisa imperativamente para divorciar. Embora os tribunais rabínicos tenham poder, em certas circunstâncias, de obrigar o marido a conceder o get, eles temem pela validade de tal ato - submetido ao 'livre arbítrio' do homem - se for conseguido por coação. Em consequência, a mulher é geralmente obrigada a comprar a sua saída do casamento, ao conceder ao marido tudo o que ele exige em termos de direitos de propriedade, pensão alimentícia, etc. Aquelas que se recusam a pagar para obter a liberdade de casar de novo não possuem nenhum recurso no sistema jurídico israelense. Elas são agunot, isto é, 'acorrentadas' ou 'ancoradas' ao próprio marido, ou mesoravot get, aquelas às quais o marido se recusa a conceder o get, sem nenhuma possibilidade de recorrer - tanto no sistema civil quanto no sistema religioso. A evolução mais preocupante nesse sentido, nos últimos anos, é o uso crescente, pelos tribunais rabínicos, de uma medida qualificada de 'bomba virtual': a invalidação retroativa do get, quando mulheres que aceitaram a extorsão de fundos e concordaram em renunciar aos próprios direitos, se retraíram depois, ao pedir reparação perante um tribunal civil (Halperin-Kaddari, 2009).

Até o presente momento, nenhum estudo empírico documentou de modo sistemático as consequências desta desigualdade de poder nos atos de divórcio. Entretanto, as organizações de mulheres dispõem de numerosos testemunhos sobre as formas de chantagem exercidas pelos maridos, e a literatura jurídica, assim como as decisões da justiça, registram os abusos cometidos. Conforme os escassos dados da pesquisa que mostram quão vulneráveis elas são naqueles casos, um terço das mulheres implicadas num processo de divórcio declarou ter sofrido pressões da parte do marido, o qual ameaçava recusar-lhes o get. Aliás, $7 \%$ delas continuam casadas, pois elas desistiram da sua vontade 
de divorciar por esse mesmo motivo e perante o risco de se tornarem agunah ou mesorevet-get. Além disso, entre as 916 mulheres entrevistadas, cerca de $40 \%$ afirmaram conhecer pessoalmente mulheres cujo pedido de divórcio serviu para lhes extorquir concessões ${ }^{4}$.

A respeito da igualdade dos sexos e do estatuto das mulheres, o peso da religião em matéria de estatuto pessoal tem outros efeitos, que dizem respeito, sobretudo, às implicações sexuais do conflito nacional. A existência do conflito israelo-árabe e o medo dos/as judeus/judias frente à 'ameaça demográfica' encarnada pelos/as árabes influem de modo decisivo sobre a vida das mulheres, definidas como 'portadoras do coletivo', pois é a maternidade que lhes dá formalmente acesso ao estatuto civil (Yuval-Davis, 1980).

O ponto culminante, a esse respeito, concerne à ausência de casamento civil. Este último está no coração de uma controvérsia (os partidos ortodoxos se opõem a ele de modo veemente, argumentando que esse tipo de união entre judeus/judias seria nocivo para a coesão do povo judeu), mesmo se não se dá a ela uma importância política maior. Os partidos no poder escolheram, com efeito, 'gerir' o problema ao ignorá-lo5, apesar do afluxo em Israel, durante os anos 1990, de imigrantes da ex-União Soviética, que não podem casar perante um rabino, por não serem reconhecidos/as como judeus/judias conforme as normas ortodoxas ${ }^{6}$. Julgada demasiadamente explosiva, essa questão ficou assim sem resposta.

\section{ORGANIZAÇÕES DE MULHERES NO SEIO DA SOCIEDADE CIVIL}

As organizações de mulheres sempre desempenharam um papel fundamental - na sociedade israelense em geral, e para a promoção

4 A pesquisa por telefone organizada pela Geocartograph, em junho de 2004, para o Centro de Promoção da Condição Feminina Ruth e Emanuel Rackman, da Universidade Bar-Han, e apresentada ao Parlamento Israelense, foi realizada junto a 916 mulheres judias (documento disponível no Centro Rackman: rackman.center@gmail.biu.ac.il).

5 Esta tática do desprezo foi facilitada por diversos episódios jurídicos, tais como o reconhecimento oficial do casamento civil, celebrado fora de Israel, ou a amplitude do reconhecimento legal concedido às uniões de fato.

6 Em 2007, os/as cidadãos/cidadãs sem pertença religiosa (de ascendência judaica, na maior parte, mas não judeus/judias conforme a definição da lei judaica) representavam 3,9\% da população de Israel, e $5 \%$ das pessoas com idade de 20 a 44 anos. 
das mulheres em particular. Em consequência, elas suscitaram muito interesse e muitas pesquisas acadêmicas (Swirski, 1993; Wenzel, 1996; Adler, Izraeli, 1998). Uma das obras mais completas nesse campo ressalta o dilema das israelenses: colocar o acento nos direitos das mulheres e no feminismo, ou manifestar sua pertença nacional e seu desejo de ser integrada. Quase todos/as os/as pesquisadores/as concordam em dizer que, apesar do grande número de associações, as mulheres não representam (e nunca representaram) uma força política de impacto real sobre a sociedade no seu conjunto. Essa relativa impotência explica-se, antes de tudo, pela prioridade que todos reconhecem tradicionalmente à construção e ao reforço da entidade política nacional judaica - uma prioridade que se exerce à custa das vozes feministas no seio da sociedade israelense (Yishai, 1997). Além disso, quando a militância (extraparlamentar) se exprimiu no plano social e político, ela assumiu, sobretudo, a forma do pacifismo de esquerda (Hasan, 1993; Herzog, 2008). Pode-se ver nisso tantos fatores decisivos que contribuem para a paralisia aparente em relação com o domínio das regras religiosas sobre o casamento e o divórcio em Israel.

Importa lembrar que a luta emblemática das sufragistas foi ocasião de impressionantes mobilizações feministas na era pré-estatal. Todavia, se a batalha pelo direito de voto, que terminou em 1925, desembocou numa inegável vitória, ela não marcou uma virada nas políticas da época. Já nos anos 1930, as reivindicações liberais a favor da igualdade política foram eclipsadas pelo conceito sionista do Movimento Socialista do Trabalho, exigindo que todos/as, homens e mulheres, se dedicassem inteiramente à construção de uma identidade judaica. As pioneiras do sufrágio feminino se retiraram, então, progressivamente da cena política, para finalmente deixar o lugar a organizações de mulheres centradas antes de tudo nas questões domésticas (Wenzel, 1996, p. 8). É nesse pano de fundo que surgiram os novos grupos feministas dos anos 1970 que, contrariamente às organizações femininas tradicionais, queriam não apenas eliminar toda discriminação para com as mulheres, mas instaurar uma mudança fundamental nas estruturas sociais de poder. Entretanto, diferentemente dos movimentos de libertação das mulheres dos Estados Unidos e de Europa ocidental, que recebiam a sua legitimidade 
do crescimento dos movimentos de protesto, as primeiras feministas israelenses enfrentaram desde o início uma desconfiança generalizada da população (e das elites políticas). No começo dos anos 1970, o seu apelo em favor de mudanças sociopolíticas corria o risco de ser percebido como ofensa à segurança nacional, mais do que como proposta de reforma das instituições.

Por isso, a maior parte dos seus esforços diziam respeito à esfera socioeconômica (isto é, as questões de redistribuição, de welfare, de divisões de classe etc.). Mesmo as organizações que renunciavam ao seu papel tradicional de provedoras de serviços para comprometer-se num trabalho de lobbying em favor de mudanças políticas e jurídicas se mantinham no quadro socioeconômico. Não se arriscaram no que é geralmente considerada como a 'verdadeira' linha de clivagem ideológica e política em Israel: a oposição direita-esquerda (que, neste país, remete ao conflito nacional) e o abismo religioso-laico.

Precisemos, além disso, que o compromisso feminista extraparlamentar procedia, sobretudo, da ala de extrema-esquerda do leque político, na forma de organizações de mulheres para a paz no começo dos anos 1980. Desde então, elas participaram ativamente do movimento 'A Paz Agora', cujo objetivo era fazer pressão sobre o governo israelense para que considerasse propostas de paz construtivas, enquanto outros grupos pacifistas começavam a se fazer ouvir, em particular durante a primeira guerra de Israel no Líbano, em 1982. Uma parte deles era composta exclusivamente por mulheres judias, enquanto outros reuniam abertamente judias e árabes. Defendendo a ideia de que as mulheres são, por essência, mais entusiastas pela paz e mais dispostas a se comprometer para preservar a vida humana (WENZEL, 1996, p. 46), eles insistiam nas consequências da orientação militar de Israel quanto à situação social e política das mulheres, mostrando que a busca da paz fazia parte de um objetivo mais ambicioso: fazer evoluir a estrutura e as prioridades das sociedades nas quais viviam as israelenses e as palestinas (Herzog, 2008).

Todavia, essa notória contribuição a favor da paz teve um efeito negativo sobre a causa mais geral do feminismo em Israel. De um lado, a atração do movimento feminista pela ala esquerda do tabuleiro político 
- embora não se deva generalizar - contribuiu às vezes para deslegitimar o movimento no seu conjunto aos olhos da opinião pública. Por outro lado, e não falta ironia aqui, as feministas mais em vista dedicavam toda a sua energia ao conflito israelo-palestino, ao passo que este servia como argumento central para rejeitar abertamente as reivindicações das muIheres e favorecer a preservação dos papeis sexuados mais tradicionais (por via da glorificação da maternidade). Desse modo, precisamente, boa parte da mobilização feminista se via canalizada numa direção pouco representativa do núcleo duro das preocupações das mulheres?

Pode-se considerar que, até certo ponto, a energia e os recursos dedicados à rejeição da guerra foram gastos em detrimento de outras causas políticas que as feministas poderiam ter apoiado. Não porque o compromisso feminista tenha que focalizar-se numa única questão por vez, nem que a defesa da paz exclua em si qualquer outro combate político, ou que haja um conflito intrínseco entre o pacifismo e a luta contra os constrangimentos religiosos e a favor do casamento civil. Contudo, a experiência israelense mostrou, na nossa opinião, que, de fato, uma das batalhas levou a melhor sobre a outra.

A esse respeito, a mobilização das mulheres no seio da comunidade religiosa judaica, de um lado, e da comunidade palestina, do outro lado, parece crucial. Não há nenhuma dúvida de que é de lá que provém os avanços mais dinâmicos resultando de iniciativas feministas em Israel, no tempo atual. Certas semelhanças caracterizam os esforços consentidos nos dois campos. De um lado e de outro, as militantes envolvidas mantêm uma relação complexa com a religião e questionam fortemente a autoridade religiosa em matéria de casamento e divórcio, embora sob dois ângulos diferentes: as primeiras, a partir de dentro da comunidade praticante judaica, e as outras, a partir de fora. O mais importante, aos nossos olhos, é que suas intervenções assumem um caráter verdadeiramente político, e isso a dois títulos: no seio das suas comunidades religiosas respectivas, elas visam a transformar a repartição sexual do poder; e na escala nacional, elas possuem um impacto político ligado à

\footnotetext{
Apesar dos numerosos escritos e dos movimentos de mulheres do mundo inteiro sobre o tema da paz, não há dúvidas de que, aos nossos olhos, as preocupações essenciais das mulheres dizem respeito às questões de estatuto pessoal.
} 
intervenção dos partidos e ao trabalho legislativo ou de lobbying. Elas representam assim duas vias de ação distintas no quadro mais largo do movimento feminista e das organizações de mulheres em Israel.

\section{FEMINISMO RELIGIOSO NO SEIO DA SOCIEDADE JUDAICA}

Dois fatores suscitaram o aparecimento do feminismo no seio da comunidade religiosa judaica em Israel: a elevação do grau de educação, tanto religiosa quanto laica, e as influências feministas procedendo, ao mesmo tempo, da sociedade laica israelense e das correntes ortodoxas modernas dos Estados Unidos. A organização Kolech (Forum Religioso das Mulheres), nascida há dez anos, desempenhou um papel-chave a esse respeito. Ao escolher o nome de Kolech ('sua voz' no feminino, uma citação do Cântico dos Cânticos, mas também uma referência deliberada às diversas regras religiosas conforme as quais a voz de uma mulher não deve se fazer ouvir em público), este movimento mostra que pretende promover a integração das mulheres em todos os níveis da vida e da comunidade religiosas. Kolech se define abertamente como feminista, bipartidária e politicamente independente (Kehat, 2005).

Além desse amplo movimento agregador, as mulheres judias praticantes criaram outros grupos feministas, na forma de organizações prestadoras de serviços - em particular para auxiliar as mulheres confrontadas aos tribunais rabínicos. Esses grupos todos estão reunidos sob o amparo de uma coligação internacional das mulheres judias criada em 1991, a ICAR - acrónimo de Coligação Internacional para os Direitos das Agunot e de uma palavra hebraica significando 'a coisa mais importante'. Nesses últimos dez anos, a ICAR demonstrou um ativismo político e jurídico intenso - lobbying parlamentar sobre as questões relativas às reformas legislativas e à nomeação dos juízes rabínicos, campanhas públicas, manifestações e outras. As ações da ICAR desembocaram na adoção, em 2008, de uma emenda à lei sobre os direitos de propriedade dos/as cônjuges de 1973, a qual cortou, uma vez por todas, o nó górdio que associava a repartição dos bens matrimoniais ao get: esta pode doravante ser feita antes da obtenção do último (Halperin-Kaddari, 2008).

Esta emenda constitui, sem dúvida nenhuma, o resultado maior de anos de luta para melhorar o estatuto das mulheres e impor o princípio 
de igualdade dos sexos no direito da família e do divórcio em Israel. As tentativas de modificar a lei quase remontam à sua adoção, em 1973, mas o establishment rabínico sempre recusou que a discussão sobre a repartição dos bens pudesse acontecer antes do get, pretendendo que seria uma incitação ao divórcio e que isso levaria também muitos casais à separação, sem divórcio religioso. Na verdade, os tribunais rabínicos e os partidos religiosos que os apoiam temiam simplesmente perder o seu controle absoluto sobre os procedimentos de separação. Assim, a luta em volta desta emenda fez coincidirem os dois campos de batalha que regem infelizmente o direito sobre o divórcio em Israel: a guerra dos sexos e a guerra entre hierarquia religiosa e sistema jurídico laico. Como ressaltou o grande rabino de Israel, Shlomo Amar: "As organizações de mulheres são o terror do país, e é culpa delas se estamos numa posição tão crítica nesta guerra"».

\section{O MOVIMENTO FEMINISTA ARABO-PALESTINO ${ }^{9}$}

O caso das cidadãs árabo-palestinas oferece um exemplo de interseccionalidade levada ao extremo, já que elas são objeto de uma tríplice discriminação: enquanto mulheres vivendo em Israel, enquanto palestinas, e enquanto membros do sexo feminino da comunidade palestina. As relações entre nacionalismo e feminismo foram ocasião de muitas pesquisas e publicações eruditas. Muitas delas concordam em dizer que o nacionalismo está, muitas vezes, na origem de uma tomada de consciência favorecendo o nascimento de um movimento feminista. Ora, as coisas nem sempre são tão simples. Prova disso é o exemplo de Israel, onde o fator religioso desempenha um papel maior no conflito

8 Citado pelo jornal quotidiano Yediot Aharonot de 01 de dezembro de 2008. Ver: www.ynet.co.il/ articles/0,7340,L-3631774,00.html

9 Aos nossos olhos, as organizações feministas árabo-palestinas são uma expressão do feminismo muçulmano. Com certeza, este movimento é mais laico que religioso e temos o direito de perguntar se a formulação é adequada. É preciso notar, todavia, que se suas aderentes não se definem necessariamente como muçulmanas (e, antes, como palestinas), elas são forçadas a enfrentar um quadro social e cultural que, formalmente, é muçulmano. O Estado lhes impõe uma pertença religiosa e as obriga a reconhecer o tribunal da charia como instância suprema que rege sua vida toda. Logo, parece nos pertinente qualificar este movimento como feminismo muçulmano. 
armado em curso. Já que suas reivindicações eram voltadas para dentro e não para fora (contra o poder estrangeiro), as feministas - judias e árabes - foram acusadas de deslealdade e sedição (Rouhana, Ghanem, 1998). Essa tensão era muito mais sensível do lado palestino, onde sua luta chegou finalmente à emenda da lei sobre a família, adotada pela Knesset em 2001, restringindo o domínio dos tribunais da charia e lhes conferindo uma competência análoga à dos tribunais rabínicos. Foi sem dúvida a conquista jurídica maior do movimento feminista palestino em Israel - ilustrando do modo mais explícito a tensão entre pertença nacional e religiosa, de um lado, e compromisso feminista, do outro lado.

Entretanto, essas batalhas geraram uma oposição muito forte, sobretudo da parte dos dirigentes muçulmanos, todos de sexo masculino. Uma reação típica foi a de Qadi Natour, presidente da Alta Corte de apelação islâmica, qualificando esta emenda de "erro grave, de envergadura quase histórica", e explicando que "O Código do estatuto pessoal se refere ao Alcorão e não ao ponto de vista individual de tal ou qual jurista, em tal ou qual momento histórico. A charia faz parte da identidade dos muçulmanos" (Justice, 1998, p. 22). Essas últimas palavras constituem a chave do problema. Esforçar-se por mudar o estatuto dos/as muçulmanos/as por via do direito da família pressupõe um combate que toca não apenas no coração do sistema progressista de liberdades civis e do conflito religioso de ordem patriarcal, mas também do conflito nacional e político em Israel. As feministas palestinas estão confrontadas com uma coligação muito especial, associando juízes dos tribunais islâmicos, dirigentes nacionalistas liberais e muçulmanos tradicionalistas, todos exigindo delas que renunciem à sua luta e se dobrem aos interesses do coletivo nacional palestino. A oposição religiosa chegou a emitir uma fatwa (veredito religioso) contra as militantes ${ }^{10}$.

$$
* * *
$$

10 A coisa foi revelada por Nasarin A'alimi, diretor do Grupo de trabalho pela igualdade perante a lei sobre o estatuto pessoal, na ocasião de uma reunião do Comité sobre a promoção do estatuto da mulher da Knessest (Parlamento), no dia 31 de maio de 2006. http://law.haifa.ac.il/ clinics/clinic4/kne.doc. 
O exame das questões que tocam às (des)igualdades de sexo, na religião e no político em Israel, supõe que se leve em conta a persistência do conflito nacional e suas implicações a respeito: da própria construção da identidade feminina, as mulheres sendo definidas como 'portadoras do coletivo' no sentido material; da importância da luta pela paz no programa de ação feminista, o que induz uma perda de legitimidade do movimento das mulheres aos olhos do resto da população judaica; da militarização cultural da sociedade israelense e do peso dos problemas de segurança na alocação dos recursos; da implicação da fratura nacional sobre as possibilidades de colaboração entre organizações feministas judaicas e árabes e, sobretudo, da manutenção de um sistema jurídico (código do estatuto pessoal) que confere à religião um controle exclusivo sobre o casamento e o divórcio. Todos esses elementos contribuem para confortar as fronteiras étnicas e nacionais, qualificando, ao mesmo tempo, as mulheres como 'portadoras do coletivo' (desta vez, no sentido jurídico-formal), e para perpetuar as desigualdades de sexo.

Tudo isso pesa sobre a causa feminista em Israel, levando a luta pela igualdade dos sexos a um impasse. Todavia, certos desenvolvimentos parecem portadores de esperança, sobretudo no decorrer da última década. Assaz paradoxalmente, esses sinais provêm das fileiras dos movimentos feministas geralmente percebidos como 'religiosos'. Como se viu, esses últimos já venceram várias batalhas jurídicas sobre questões entre as mais urgentes - principalmente a do estatuto pessoal.

Traduzido do inglês por Jacqueline Heinen

\section{REFERÊNCIAS}

ABDO, Nala. Muslim Family Law: Articulating Gender, Class, and the State. International Review of Comparative Public Policy, n 9, 1997.

ABOU-RAMADAN, Moussa, MONTERESCU, Daniel. Islamic Ruling in a 'Jewish and Democratic' State: Cooptation through Islamization of the Shari`a Field. Mishpat Umimshal, vol. $11, \mathrm{n}^{\circ} 1$, p. 2008.

ADLER, Nancy J., IZRAELI, Dafna N. Women in Management Worldwide. New York: M. E. Sharpe, 1988I.

BEN-ELIEZER, Uri. A Nation-in-Arms: State, Nation, and Militarism in Israel's First Years.

Comparative Studies in Society and History, vol. 37, $n^{\circ} 2,1995$. 
BEN-SHEMESH, Yaacov. Constitutional Rights, Immigration and Demography. Mishpat Umimshal, vol. 10, $n^{\circ} 1,2006$.

DAVIDOV, Guy, YOVEL, Jonathan, SABAN, Ilan [et al]. State or Family? The Citizenship and Entry to Israel Act. Mishpat Umimshal, $n^{\circ}$ 8, 2005.

FALK, Ze'ev W. The Divorce Action by the Wife in Jewish Law. Jerusalem: Institute for Legislative Research and Comparative Law, 1973.

FOGIEL-BIJAOUI, Sylvia. Why Won't There be Civil Marriage any Time Soon in Israel?. Nashim: A Journal of Jewish Women's Studies \& Gender, n 6, 2003.

HALPERIN-KADDARI, Ruth. Gender Construction under Halachic Marriage and Divorce Laws. Talpiot, $\mathrm{n}^{\circ} 22,2000$.

HALPERIN-KADDARI, Ruth. Women in Israel: A State of Their Own. Philadelphia: University of Pennsylvania Press, 2004.

HALPERIN-KADDARI, Ruth. The 'Get' gets Fairer. Jerusalem Post, 18 Novembro, 2008. HALPERIN-KADDARI, Ruth. The Missing Women's Enigma: The Scope of the Get. Refusals Predicament in Israel. Kolech - Being A Jewish Woman, $n^{\circ}$ 5, 2009.

HALPERIN-KADDARI, Ruth, YADGAR, Yaacov. Religion, Politics and Gender Equality among Jews in Israel. Mimeo. Geneva: UNRISD, Outubro, 2009.

HASAN, Manar. Growing up Female and Palestinian in Israel. In: SWIRSKI, Barbara, SAFIR Marilyn P. (Eds.). Calling the Equality Bluff: Women in Israel. New York: Teachers College Press, 1993.

HAUT, Irwin. Divorce in Jewish Law and Life. New York: Sepher-Hermon Press, 1983. HERZOG, Hanna. Re/visioning the Women's Movement in Israel. Citizenship Studies, vol. 12, $\mathrm{n}^{\circ} 3,2008$.

Justice. Moslem Shari'a Courts should be left to its own Creative Devices - Conversation with Qadi Ahmad H. Natour, n 17, 1998.

KEHAT, Hannah. Opening to the Fifth Conference. Kolech - Being A Jewish Woman, $\mathrm{n}^{\circ} 5,2005$.

LEVY, Shlomit, LEVINSON, Hanna, KATZ, Elihu. Beliefs, Observances, and Social Interaction among Israeli Jews. Jerusalem: The Gutman Israel Institute of Applied Social Research, 1993.

ROSEN-ZVI, Ariel. Israeli Family Law: The Sacred and the Secular. Tel Aviv: Tel Aviv University Press, 1990.

ROUHANA, Nadim, GHANEM, Asad. The Crisis of Minorities in Ethnic States: The Case of Palestinian Citizens in Israel. International Journal of Middle East Studies, vol. 30, $\mathrm{n}^{\circ} 3,1998$.

SHACHAR, Ayelet. Citizenship and Membership in the Israeli Polity. In: ALEINIKOFF, Alexander, KLUSMEYER, Douglas (Eds.). From Migrants to Citizens: Membership in a Changing World. Washington DC, Brookings Institution Press, 2000. 
SHIFMAN, Pinhas. Family Law in Israel. Jerusalem, Hebrew University Press, 1995.

SMOOHA, Sammy. Ethnic Democracy: Israel as an Archetype. Israel Studies, vol. 2, $\mathrm{n}^{\circ}$ 2, 1997.

STOPLER, Gila. Israel's Natality Policy and the Rights of Women and Minorities. Mishpat Umimshal, vol. 11, $n^{\circ} 1,2008$.

SWIRSKI, Barbara. Israeli Feminism New and Old. In: SWIRSKI, Barbara, SAFIR Marilyn P. (Eds.). Calling the Equality Bluff: Women in Israel. New York: Teachers College Press, 1993.

WENZEL, Mirjam. Women's Movements in Israel. Jerusalem: Hans Ebert Foundation, 1996.

YISHAI, Yael. Between the Flag and the Banner: Women in Israeli Politics. Albany State: University of New York Press, 1997.

YUVAL-DAVIS, Nira. The Bearers of the Collective: Women and Religious Legislation in Israel. Feminist Review, $\mathrm{n}^{\circ}$ 4, 1980.

ZILBERSHATS, Yaffa. Coping With the Non-Jewish Immigration to Israel. Mishpat Umimshal, vol. 10, $\mathrm{n}^{\circ} 1,2006$. 